\section{An application profile and prototype metadata management system for licensed electronic resources}

In the fall of 2000 , my supervisor Karen Calhoun asked me to look into the possibility of building a local database system to help manage electronic resource licensing and also mentioned that the deadline for the ACRL Samuel Lazerow Fellowship proposals was approaching. I set to work writing the proposal, which helped me collect my thoughts on the issue. My intention was to do some research and start constructing a system that could be used at Cornell and perhaps adapted for use in other libraries, as well. Around the same time I learned that Tim Jewell, head of collection management services at the University of Washington, was pursuing a similar research thread. We communicated by email and agreed to share information.

Jewell had already gathered a good deal of information and made contacts with pioneers who were involved with building local electronic resource management systems for their libraries. That winter I began working on a Web site that would tie what Jewell was uncovering with information I was finding. The Web site became known as the Web Hub (www. library.cornell.edu/cts/elicensestudy/), and it has served the exact function intended by drawing together people who are working on this problem.

That spring I was awarded the Samuel Lazerow Fellowship, which helped to support travel and subsequent important conference calls related to this project.

In the summer of 2001, Jewell's report, "Selection and Presentation of Commercially Available Electronic Resources: Issues and Practices" (available online at www.clir.org/pubs/reports/pub99/ contents.html), was published by the Digital Library Federation (DLF) and the Council on Library and Information Resources (CLIR). This seminal document defines the main management issues facing libraries as serials content migrates from print to digital, from ownership to access.

In the course of writing the DLF/CLIR report, Jewell developed a relationship with the very supportive Dan Greenstein, then head of DLF. Greenstein was instrumental in helping us bring together other $\mathrm{li}^{-}$ braries and interested vendors, plus NISO's Pat Harris, for the "NISO/Digital Library Federation Workshop," held on May 10, 2002, a half-day prestandardization workshop to examine standards needed to facilitate the management of electronic resources. The workshop broke new ground and made clear that the library community was ready to put some work into trying to standardize the way in which we handle electronic resources.

A core steering group of librarians was assembled and a proposal for the Electronic Resource Management Initiative (www.diglib.org/standards/dlf-erm02.htm) was submitted to DLF and accepted. Members of the hard-working steering group are Ivy Anderson (Harvard), Sharon Farb (UCLA), Kimberly Parker (Yale), Angela Riggio (UCLA), and Nathan Robertson (Johns Hopkins), plus Jewell and myself.

The project will culminate with a presentation at the 2003 DLF Fall Forum, where the steering group will present a number of deliverables designed to facilitate the management of electronic resources. These deliverables will define functional requirements, elements, and a model system, along with research into the possible use of XML as a markup standard (www.library.cornell.edu/cts/ elicensestudy/dlfdeliverables/home.htm).

Although I haven't built a local system for Cornell, to a significant extent the work we have contributed to the DLF initiative is setting the framework for the creation of electronic resource management systems that will be built for Cornel! and others.-Adam Chandler, Comell University, Jalc28@comell.edu 